\title{
Impact of American College of Cardiology/American Heart Association Guidelines 2017
}

\author{
${ }^{1}$ Mahim Saran, ${ }^{2}$ Sudhanshu K Dwivedi
}

\begin{abstract}
Reduction in the level of blood pressure (BP) from 140/90 to $130 / 80 \mathrm{~mm} \mathrm{Hg}$ for defining hypertension is one of the major practice changing modifications of the 2017 American College of Cardiology/American Heart Association guidelines which are bound to have a huge societal impact. The number of hypertension patients will increase 1.5 times after this definition change. Although the BP levels for defining hypertension have changed, the levels at which pharmacological therapy should be started have remained the same, i.e., $\geq 140 / 90 \mathrm{~mm} \mathrm{Hg}$ (Stage 2 hypertension according to newer guidelines) except in special situations (clinical atherosclerotic cardiovascular disease or estimated 10 -year cardiovascular disease risk of $\geq 10 \%$ ). All in all, definitely these guidelines are more comprehensive, give a much more clarity to the treating physician, and are aimed at better long-term prevention of target-organ damage. But at the same time, they leave us in the same dilemma which arises after every major guideline change: how to deal with patients who are being treated as per the old guidelines?
\end{abstract}

Keywords: Guidelines, Hypertension, Noncommunicable disease.

How to cite this article: Saran M, Dwivedi SK. Impact of American College of Cardiology/American Heart Association Guidelines 2017. Hypertens J 2017;3(4):193-195.

Source of support: Nil

Conflict of interest: None

\section{INTRODUCTION}

The definitions and practice guidelines of hypertension have been continuously changing over a period of time. The new hypertension guidelines published on November 14, 2017 is another effort toward a more systematic and comprehensive evaluation and treatment of hypertension. The newer guidelines provide a more systematic approach toward when to make a diagnosis of hypertension, when to start lifestyle modifications, and when to start pharmacotherapy. Reduction in the level of BP from 140/90 to $130 / 80 \mathrm{~mm} \mathrm{Hg}$ for defining hypertension is one of the

\footnotetext{
${ }^{1}$ Fellow Interventional Cardiology, ${ }^{2}$ Professor

1,2Department of Cardiology, King George's Medical University Lucknow, Uttar Pradesh, India
}

Corresponding Author: Sudhanshu K Dwivedi, Professor Department of Cardiology, King George's Medical University Lucknow, Uttar Pradesh, India, e-mail: dr_skdwivedi@rediffmail. com major practice changing modifications which are bound to have a huge societal impact.

\section{DEFINITION CHANGE: IS IT JUST NUMBERS?}

Although the BP levels for defining hypertension have changed, the levels at which pharmacological therapy should be started have remained the same, i.e., $\geq 140 / 90$ $\mathrm{mm} \mathrm{Hg}$ (Stage 2 hypertension according to newer guidelines) except in special situations (clinical atherosclerotic cardiovascular disease or estimated 10-year cardiovascular disease risk of $\geq 10 \%$ ).

Lowering the BP levels for defining hypertension means that a large group of population which was earlier considered as normotensive will be now considered as hypertensive. For example, according to Joint National Committee (JNC 7) definition, $32 \%$ of the adult population of the United States was hypertensive which has increased to $46 \%$ after the definition change. ${ }^{1}$ A similar increase in the prevalence of hypertension by 1.5 times may be seen in Indian scenario also. At the same time, the number of hypertensives on pharmacological therapy will remain more or less the same in general population without high-risk features.

So, can we say that the newer guidelines will just change the current statistics? Probably not:

- By labeling patients with BP more than $130 / 80 \mathrm{~mm}$ $\mathrm{Hg}$ as hypertensives, lifestyle modifications (nonpharmacological interventions) can be initiated early and likely to be more acceptable

- This gives a lot of time for patient education and bringing disease awareness

- Closer follow-up of hypertensive patients who are not yet requiring pharmacotherapy (stage 1 hypertension) ensures earlier initiation of pharmacotherapy

- This might go a long way in preventing target organ damage.

Is it really as good as it sounds? Again, probably not:

An almost $50 \%$ increase in prevalence is not just a number. As far as psychosocial impact of the disease is concerned, numbers do matter!!!

\section{SO WHY WERE THE TARGETS LOWERED?}

A large meta-analysis has shown that with every $20 \mathrm{~mm} \mathrm{Hg}$ systolic and $10 \mathrm{~mm} \mathrm{Hg}$ diastolic rise in $\mathrm{BP}$ (starting from $115 / 75$ to $180 / 110 \mathrm{~mm} \mathrm{Hg}$ ), the cardiovascular mortality 
doubles. ${ }^{2}$ If this is true, then the BP target should have been $120 / 80 \mathrm{~mm} \mathrm{Hg}$. However, if we analyze the metaanalysis published in Lancet in 2014, although the relative risk reduction remains the same for all subgroups with every $20 / 10 \mathrm{~mm} \mathrm{Hg}$ fall, absolute risk reduction is dependent upon the baseline risk of individuals, i.e., the number needed to treat for prevention of one event will be much less in high-risk group as compared with the low-risk group. ${ }^{3}$ The same was shown in Systolic Blood Pressure Intervention (SPRINT) trial where high-risk hypertensive patients had $27 \%$ relative risk reduction in mortality and $25 \%$ relative risk reduction in cardiac events from bringing down BP from 140/90 to 120/80 mm Hg. In addition, the Medical Research Council (MRC) trial showed that the number needed to treat for preventing one stroke was 791 for 1 year and no benefit in preventing coronary events in low-risk prehypertensive patients. ${ }^{5}$ Similarly, the Heart Outcomes Prevention Evaluation 3 (HOPE 3) trial showed that there was no benefit in reducing $\mathrm{BP}$ below $140 / 90 \mathrm{~mm} \mathrm{Hg}$ in intermediate-risk patients. ${ }^{6}$

Furthermore, the SPRINT trial used oscillometric method for measuring BP where $120 / 80 \mathrm{~mm} \mathrm{Hg}$ is equivalent to $130 / 80 \mathrm{~mm} \mathrm{Hg}$ by manual method. Hence, the target for high-risk group was set at 130/80 $\mathrm{mm} \mathrm{Hg}$.

\section{CHANGING TREATMENT TARGETS: A CLINICAL CHALLENGE, A SOCIOECONOMIC BURDEN OR NEED OF THE HOUR?}

Another important change that these new guidelines have brought about is the revision of treatment target to $<130 / 80 \mathrm{~mm} \mathrm{Hg}$.

If we look at the data from the Prospective Urban and Rural Epidemiological (PURE) study, only $40 \%$ of the hypertensives receiving treatment had $\mathrm{BP}<140 / 90 \mathrm{~mm} \mathrm{Hg}$. Numbers are still less (12.7\%) if we include those unaware of the disease and those not receiving treatment. ${ }^{7}$ By taking the BP target further down, the number of people with adequate BP control will decrease further.

Achieving new targets will be a clinical challenge and the reasons are manifold:

- A lot of patients in the BP range of $130 / 80$ to $140 / 90$ $\mathrm{mm} \mathrm{Hg}$ who were being assured that their hypertension is being adequately controlled will now have to be conveyed that they need to maintain lower targets.

- Even for elderly patients, the systolic BP targets have been revised to $<130 \mathrm{~mm} \mathrm{Hg}$ except in situations where clinical judgment precludes intensive control.

- With the ever-increasing prevalence of noncommunicable diseases, balancing the drug-drug interactions and drug side effects with clinical benefit is not an easy task.

- Further lowering the targets will not only add to the pill burden but also increase in cost therapy—an addition to the economic burden, especially in the low-income households.

Another important change is the recommendation to start with two antihypertensives in stage 2 hypertension ( $\mathrm{BP} \geq 140 / 90 \mathrm{~mm} \mathrm{Hg}$ ). When to start with two drugs has always been a confusion, as there was never a clear-cut recommendation. This will come as a relief, especially to general physicians.

Newer guidelines have also clarified the concept of masked and white-coat hypertension further, with clearcut suggestions on how to deal with these situations. The importance of home BP monitoring and ambulatory BP monitoring could not have been stressed in a better way. Even the nonpharmacological therapy has been given its due importance and has been very distinctly and precisely mentioned.

\section{PSYCHOSOCIAL AND ECONOMIC IMPACT}

After pondering upon the fact that strict control is required for clinical benefit, now it is necessary to talk about the problems associated. Hypertension is a chronic disease and once labeled, it is for a lifetime. Studies have shown that patients being labeled as hypertensive may adopt a sick role and in turn affect their quality of life. ${ }^{8}$ The association of psychological distress with hypertension may be directly due to BP, side effects of medications, or the consequence of being labeled as hypertensive. Like other chronic illnesses, hypertension also has immense emotional impact leading to anxiety and depression. ${ }^{9,10}$

India is a developing country and comes under lowincome countries. Expenditure on health is of utmost importance and should be properly looked after. Strict control of BP results in multidrug prescriptions which in turn leads to higher economic burden and poorer compliance. Not only this, multidrug therapy leads to higher incidence of side effects. In 2004, the annual income loss due to noncommunicable diseases was 251 billion rupees and that due to hypertension alone was 43 billion rupees. ${ }^{11}$ The benefit of treating high-risk group is acceptable but for patients in low-risk category, aggressive treatment is only going to add to the economic burden (as emphasized in these guidelines).

The impact of these guidelines is manifold. The emphasis should be on high-risk population and strict control of BP has the maximum benefit in this subgroup.

All in all, definitely these guidelines are more comprehensive, give much more clarity to the treating physician, and are aimed at better long-term prevention of targetorgan damage. But at the same time, they leave us in the same dilemma which arises after every major guideline change- - how to deal with patients who are being treated as per the old guidelines. 
In the present scenario, where the noncommunicable diseases are toward a rising trend, the newer guidelines are very much welcome, but then all good things come with a pinch of salt.

\section{REFERENCES}

1. Muntner P, Carey RM, Gidding S, Jones DW, Taler SJ, Wright JT, Whelton PK. Potential U.S. Population Impact of the 2017 American College of Cardiology/American Heart Association High Blood Pressure Guideline. Circulation 2018 Jan;137(2):109-118.

2. Lewington S, Clarke R, Qizilbash N, Peto R, Collins R; Prospective Studies Collaboration. Age-specific relevance of usual blood pressure to vascular mortality: a meta-analysis of individual data for one million adults in 61 prospective studies. Lancet 2002 Dec;360(9349):1903-1913.

3. Blood Pressure Lowering Treatment Trialists' Collaboration. Blood pressure-lowering treatment based on cardiovascular risk: a meta-analysis of individual patient data. Lancet 2014 Aug;384(9943):591-598.

4. SPRINT Research Group; Wright JT Jr, Williamson JD, Whelton PK, Snyder JK, Sink KM, Rocco MV, Reboussin DM, Rahman M, Oparil S, et al. A randomized trial of intensive versus standard blood-pressure control. N Engl J Med 2015 Nov;373(22):2103-2116

5. Medical Research Council Working Party on Mild Hypertension. MRC trial of treatment of mild hypertension: principal results. Medical Research Council Working Party. Br Med J (Clin Res Ed) 1985 Jul;291:97.

6. Lonn EM, BoschJ, López-Jaramillo P, Zhu J, Liu L, Pais P, Diaz R, Xavier D, Sliwa K, Dans A, et al. Blood-pressure lowering in intermediate-risk persons without cardiovascular disease. N Engl J Med 2016 Apr;374(21):2009-2020.

7. Rao D. Epidemiology of hypertension in India: insights from PURE. J Indian Coll Cardiol 2015 Mar;5(Suppl 1):S28-S32.

8. Pickering TG. Now we are sick: labeling and hypertension. J Clin Hypertens (Greenwich) 2006 Jan;8(1):57-60.

9. DeJean D, Giacomini M, Vanstone M, Brundisini F. Patient experiences of depression and anxiety with chronic disease: a systematic review and qualitative meta-synthesis. Ont Health Technol Assess Ser 2013 Sep;13(16):1-33.

10. Vetere G, Ripaldi L, Ais E, Korob G, Kes M, Villamil A. Prevalence of anxiety disorders in patients with essential hypertension. Vertex 2007 Jan-Feb;18(71):20-25.

11. Mahal, A.; Karan, A.; Engelgau, M. Health Nutrition and Population (HNP) discussion paper. The economic implications of non-communicable disease for India. Washington (DC): The World Bank; 2010. 